\title{
The minimally invasive right vertical infra- axillary lateral minithoracotomy approach for the heart valve surgery: Report of 115 cases
}

\author{
Mahmut Akyıldız ${ }^{1}$, Ahmet Refik Turgut ${ }^{1}$, Taner Şerif Küçükcerit ${ }^{2}$, Güzin Kaşo², \\ Remzi Tosun ${ }^{1}$, Noyan Temuçin Oğuş ${ }^{1}$
}

1) Department of Cardiovascular Surgery, Medistate Kavacık Hospital, Istanbul, Turkiye

2) Department of Anesthesiology, Medistate Kavacık Hospital, Istanbul, Turkiye

\begin{abstract}
Objective: We have developed a minimally invasive technique for heart valve replacements through a lateral minithoracotomy via a small right infra-axillary skin incision, and have evaluated its initial results.

Methods: Through right vertical infra-axillary lateral minithoracotomy incision (by third intercostal space), 106 patients with rheumatic heart valve disease underwent heart valve surgery, 4 patients with left atrial myxsoma and 5 patient with large atrial septal defect underwent open heart operation are included in this study from July 2012 to December 2015.

Results: 42 isolated mitral valve replacements, 7 mitral valve replacements and DeVega tricuspid annuloplasty, 3 mitral and tricuspid valve replacement, 2 mitral valve replacement and right coronary artery bypass graft, 1 reoperative mitral valve replacement due to dejeneration of the bioprothesis of the mitral valve, 6 mitral valve repair, 1 mitral valve repair and aortic valve replacement; 33 isolated aortic valve replacements, 9 aortic and mitral double valve replacements, 2 triple valve replacements, 4 excision of the left atrial myxsoma and 5 surgical closure of the large atrial septal defect were performed. There were 52 women (45\%) and 63 men (55\%). The mean and range of age was $48 \pm 9$ (14-91). The length of the incision averaged $8.5 \pm 0.5 \mathrm{~cm}$, There were 4 operative mortalities, one patient from infective endocarditis and multisystem organ failure, the other patients from cardiac failure in the hospital. The results of follow up for other patients were fine.
\end{abstract}

Conclusions: This minimally invasive right vertical infra-axillary lateral minithoracotomy approach is safely, practicable, useful, economic, small wounded, cosmetic, contemporary and modern approach for the heart valve surgery

Keywords: infra-axillary, minithoracotomy, minimally-invasive cardiac surgery 


\section{Introduction}

The operation for valve replacement and repair over the past 40 years has evolved to using a median sternotomy incision, cardiopulmonary bypass, varing degrees of systemic hypothermia, antegrade and retrograde cardioplejic myocardial protection. With the establishment of the minimally invasive major surgery in orthopedic, gynecologic, urologic, general surgery and thoracic surgery over the past 25 years, cardiac surgeons over the past 15 years have begun to explore the use of minimally invasive approaches for patients undergoing standard cardiac valve operations. Minimally invasive valve surgery was first performed by Navia et al. in 1996, and by Cohn et al. in 1997. ${ }^{(1,2)}$

\section{Material and Methods}

From July 2012 to December 2015, 115 operations using a minimally invasive approach through the right vertical infra-axillary lateral minithoracotomy incision (by intercostal space) were performed in the our clinic. 106 patients with rheumatic heart disease underwent heart valve replacement and 4 patients with left atrial myxsoma and 5 patient with large atrial septal defect underwent open heart operation are included in this study. All patients were entered into the our clinic's cardiac surgery database to prospectively document preoperative indications, in-hospital and post-hospital operative morbidity and mortality, patient satisfaction was analyzed which included reliance on pain medicine and return to full activity.

\section{Operative Techniques}

Setting of the patient is left lateral decubitus and slightly posterior oblic position $\left(10^{\circ}-20^{\circ}\right.$ posterior oblic, left decubitus, right lateral thoracotomy position) with a support under patient's back. The patients undergoing heart valve replacement were treated by using a minimally invasive approach through the right vertical infra-axillary lateralminithoracotomy incision usually by third intercostal space for our operation, sometimes by fourth intercostal space for some patients which have tall and bulky body, the incision is made approximately 6 to $10 \mathrm{~cm}$ in the right infra-axillary, oblic, lateral minithoracotomy. After the incision, pulmonary tidal volume is decreased about half of the tidal volume and respiratory rate is increased to $16-18$ breaths per minute. This manipulation is usually sufficient for exposure of the pericardium, therefore we don't needusingdouble-lumen endotracheal Carlens tube for selective pulmonary ventilation. Then right pulmonary lobes can easily beretracted posteriorly using a pulmonary retractor and pericardium is opened 3-4 $\mathrm{cm}$ anterior to the phrenic nerve. The edges of the pericardium are attached to the skin by retraction stitches. This pericardial retraction raises the heart 4 to $5 \mathrm{~cm}$ to the operative field. The aorta, right and left atrium, superior and posterior vena cava are exposed. After heparinization, the femoral arter is cannulated with standard femoral artery canula, superior and inferior vena cava are cannulated with curved venous canulas.

After cannulation, cardiopulmonary bypass is begun and systemic temperature is lowered to $28^{\circ} \mathrm{C}$. Caval tapes are put down. The aorta is cross-clampedwith a spesific flexible minimally invasive cross-clamp. Antegrade cold blood cardioplegia solution is delivered for cardiac arrest. The right atrium is opened and a retrograde cardioplegia cannula is inserted after placement of purse string sutures to the coronary sinus ostium, thenantegrade and retrograde cold blood cardioplegyc solution are administered for cardiac arrest and myocardial protection and than the cardiac valve replacement or repair is performed usingthe standart techniques. All valve repair operations are checked by intraoperative transesophageal echocardiography.

\section{Results}

Table 1 lists demographics for patients undergoing minimally invasive valve surgery, including age, gender, functional class and valve etiology. Table 2 lists operative procedures of minimally invasive cardiac valve surgery. Table 3 outlines operative mortality and postoperative morbidity. The postoperative mortality for minimally invasive cardiac valve surgery was 4 $(3.47 \%)$ of 115 .

In the mitral valve group, 42 patients $(36.52 \%)$ had isolated mitral valve replacement (MVR), 7 patients (6.08\%) had MVR and DeVega Trikuspid Annuloplasty, 3 patients $(2.61 \%)$ had mitral and trikuspid valve replacement, 2 patients $(1.74 \%)$ had mitral valve replace- 
ment and right coronary artery bypass graft, 1 patient $(0.87 \%)$ had reoperative mitral valve replacement due to dejeneration of the bioprothesis of the mitral valve, 6 patients $(5.22 \%)$ had mitral ring annuloplasty which included The St Jude Saddle ring annuloplasty, showed minimal to trace mitral regurgitation by intraoperative and postoperative transesophageal echocardiography and 1 patient $(0.87 \%)$ had mitral ring annuloplasty and aortic valve replacement.

In the aortic valve group, 33 patients $(28.69 \%)$ had isolated aortic valve replacement (AVR) and 9 patients

\section{Table 1. Demographics for patients}

\begin{tabular}{|c|c|c|}
\hline Diagnosis & Patients & \\
\hline MVR was operated, isole MR & 17 & \\
\hline MVR was operated, MS and MR / & 7.7 & 9.2 \\
\hline complex mitral valve disease & 25 & \\
\hline Mitral and tricuspid valve disease & 10 & \\
\hline $\begin{array}{l}\text { Isole MR and Right coronary } \\
\text { artery disease }\end{array}$ & 2 & \\
\hline Mitral bioprotez restenozu & 1 & \\
\hline MRA was operated, isole MR & 6 & \\
\hline Isolated aortic valve insufficiency & 9 & \\
\hline $\begin{array}{l}\text { Complex aortic valve disease } \\
\text { I AS and AI }\end{array}$ & 24 & \\
\hline Aortic and mitral valve disease & 9 & \\
\hline Three valves disease & 2 & $44-38.26 \%$ \\
\hline Myxsoma & 4 & \\
\hline Large asd & 5 & $9-7,82 \%$ \\
\hline Total & 115 & $115-100 \%$ \\
\hline
\end{tabular}

MVR: mitral valve replacement MR: mitral regurgitation MS: mitral valve stenosis MRA: mitral ring annuloplasty Al: aortic valve insufficiency AS: aortic valve stenosis
(7.83\%) had aortic and mitral valve replacements and 2 patients $(1.74 \%)$ had triple valve replacements.

For isolated mitral valve replacement (MVR), arrest times averaged $(69.5+/-10)$ min, cardiopulmonary bypass times averaged $(98.5+/-10) \mathrm{min}$.

For isolated aortic valve replacement (AVR), arrest times averaged (79.2 +/- 15) min, cardiopulmonary bypass times averaged $(110.7+/-15) \mathrm{min}$.

For aortic and mitral valve replacement (AVR and MVR), arrest times averaged (141.6.5 +/- 20) min, car-

Table 2. Minimally invasive cardiac valve surgery

\section{Operative Procedures of the Minimally Invasive} Cardiac Surgery

\begin{tabular}{|l|l|l|}
\hline Mitral Valve Replacement (MVR) & 42 & $(36,52 \%)$ \\
\hline $\begin{array}{l}\text { MVR + DeVega Tricuspid } \\
\text { Annuloplasty }\end{array}$ & 7 & $(6.08 \%)$ \\
\hline $\begin{array}{l}\text { MVR + Tricuspid Valve } \\
\text { Replacement }\end{array}$ & 3 & $(2.61 \%)$ \\
\hline MVR + CABGX1 (SV-RCA) & 2 & $(1.74 \%)$ \\
\hline Redo MVR & 1 & $(0.87 \%)$ \\
\hline Mitral Ring Annuloplasty & 6 & $(5.22 \%)$ \\
\hline Mitral Ring Annuloplasty + AVR & 1 & $(0.87 \%)$ \\
\hline Aortic Valve Replacement (AVR) & 33 & $(28.69 \%)$ \\
\hline Aortic and Mitral Valve Replacement & 9 & $(7.83 \%)$ \\
\hline -- previous CMC operation & 1 & \\
\hline -- with enlargement of aortic annulus & 1 & \\
\hline --double bioprothesis valve & 2 & $(3.48 \%)$ \\
\hline Triple Valve Replacement & 2 & $(1.74 \%)$ \\
\hline Myxsoma & 115 & $(100 \%)$ \\
\hline Surgical closure of the large ASD & 5 & \\
\hline Total & & \\
\hline
\end{tabular}

MVR: mitral valve replacement AVR: aortic valve replacement CABG: coronary artery bypass grefting operation SV: saphenous vein RCA: right coronary artery CMC:Closed Mitral Commissurotomy 
diopulmonary bypass times averaged $(175.3+/-20) \mathrm{min}$.

Ventilator periods averaged $(7.5+/-2.5)$ hour, chest tube drainage averaged $(350+/-150) \mathrm{ml}$. Two patients were reoperated on for bleeding. There were zero wound infections of the thoracic and groin incisions. The length of the incision averaged $(8.5+/-0.5) \mathrm{cm}$.

In the medium-term follow-up extending to December 2015, there was four hospital death, one of these hospital mortalities was in class IV patients from endocarditis, the other all patients improved at least two functional classifications in The New York Heart.

\section{Discussion}

Cardiac valve replacement and repair for the adult patient has become an exceedingly effective operative therapy for congenithal, rheumatismal, degenerative lesions of both the aortic and mitral valve. These operations over the past 40 years have been performed through the standard complete median sternotomy and cardiopulmonary bypass with intrathoracic canulations. With the advent of minimally invasive cardiac valve surgery, several new observations have arisen regarding the treatment of patients with isolated valve

Table 3. Minimally invasive valve surgery operative Morbidity and mortality

\begin{tabular}{|l|c|}
\hline $\begin{array}{l}\text { Due to pleural hemoragyc effusion, } \\
\text { torasentesis }\end{array}$ & 5 \\
\hline Pericardial effusion & $(-)$ \\
\hline Elevation of the right diagraphma & 3 \\
\hline Groin complications & $(-)$ \\
\hline Intraoperative dissection & $(-)$ \\
\hline Reoperation on for bleeding & 2 \\
\hline Mean RBCs used & 2.4 \\
\hline Postoperative IABP required & 5 \\
\hline Postoperative ECMO required & 2 \\
\hline Endocarditis & 1 \\
\hline Mortality & 4 \\
\hline
\end{tabular}

disease. Certainly, trauma is considerably less with the minimally invasive incisions. Sternal infections are avoided and there is less blood loss from the incision and the operative site. ${ }^{(2)}$

Minimally invasive valve surgery was first performed by Navia et al. in 1996, and by Cohn et al. in 1997. ${ }^{(1,2)}$ When compared with a standard median sternotomy approach, the reported benefits of minimally invasive valve surgery include: reduced blood loss and pain, a lower morbidity, an enhanced recovery with shorter intensive care unit and hospital length of stay. ${ }^{(2-8)}$ Overall, the studies performed have involved single valve surgery in lower risk patients.

Lamelas et al. have compared the outcomes of minimally invasive valve surgery with median sternotomy in high risk patients, ${ }^{(9)}$ Lamelas have demonstrated a reduced morbidity and lower resource utilization in those patients with chronic kidney disease, ${ }^{(10)}$ chronic obstructive pulmonary disease, ${ }^{(11)}$ those requiring reoperative mitral valve ${ }^{(12)}$ and aortic valve ${ }^{(13)}$ surgery. In addition, they observed a reduction in mortality in the elderly $^{(14)}$ and obese ${ }^{(15)}$ patients. Because of these benefits, especially in high risk patients, it is reasonable to hypothesize that those needing concomitant aortic and mitral valve surgery would also benefit from a minimally invasive approach.

In this our series of 96 patients, only 2 patients had to revision for the postoperative bleeding, whereas mean RBCs usage was $2.4 \mathrm{U}$ in the our minimally invasive valve surgery group. There is improved cosmetic with these incisions which are relatively small, particularly for slim, underweight patients.

Techniques of minimally invasive surgery include for mitral valve, a port access system, ${ }^{(16)}$ which actually does mitral valve surgery through an even smaller transverse incision under the right breast fold and is more cosmetically; for aortic valve partial upper $\mathrm{T}$ or $\mathrm{L}$ shaped ministernotomy or right anterior minithoracotomy; ${ }^{(17)}$ for combined aortic and mitral valve surgery, a minimally invasive approach, performed via a right anterolateral thoracotomy (The "Miami Method"); ${ }^{(9)}$ for double or triple valve performed via a right anterolateral thoracotomy by Karimov et al. in $2009^{(18)}$ and $2010^{(19)}$ 
For single, double, even triple valve replacement operations, surgical closure of the large ASD, myxsoma excision, concomitant AF ablation and concomitant right coronary artery bypass grafting operations, performed via a right vertical infra-axillary lateral minithoracotomy by our surgical team. This minimally invasive techniques for mitral or aortic valve performed by Wang et al. in $1999,{ }^{(20)}$ for mitral valve performed by Tüneriret al. in $1999^{(21)}$ and Beşoğul et al. in 2002, ${ }^{(22)}$ for aortic valve performed by Ito et al. in 2015. ${ }^{(23)}$

In 1996, Carpentier performed the first video-assisted minimally invasive mitral valve surgery (MIMVS) through a mini-thoracotomy ${ }^{(24)}$ and Chitwood introduced the transthoracic aortic clamp. ${ }^{(25)}$ In 1998, Mohr developed a video-assisting port access technology to reduce CPB and cross-clamp times which allowed a better visualization of the valve. ${ }^{(26)}$

Since then, MIMVS has been performed through a wide variety of approaches (hemisternotomy, parasternal incision, mini-thoracotomy, total endoscopically and robotically) with favourable long-term outcomes even in elderly and redo patients when compared with sternotomy despite longer bypass and cross-clamp times. ${ }^{(27-28)}$ However, minimally invasive cardiac surgery is always accompanied by a learning curve.

The pain in these incisions is considerably less than in the patients with the median sternotomy, especially late period after the surgery. There is significantly less

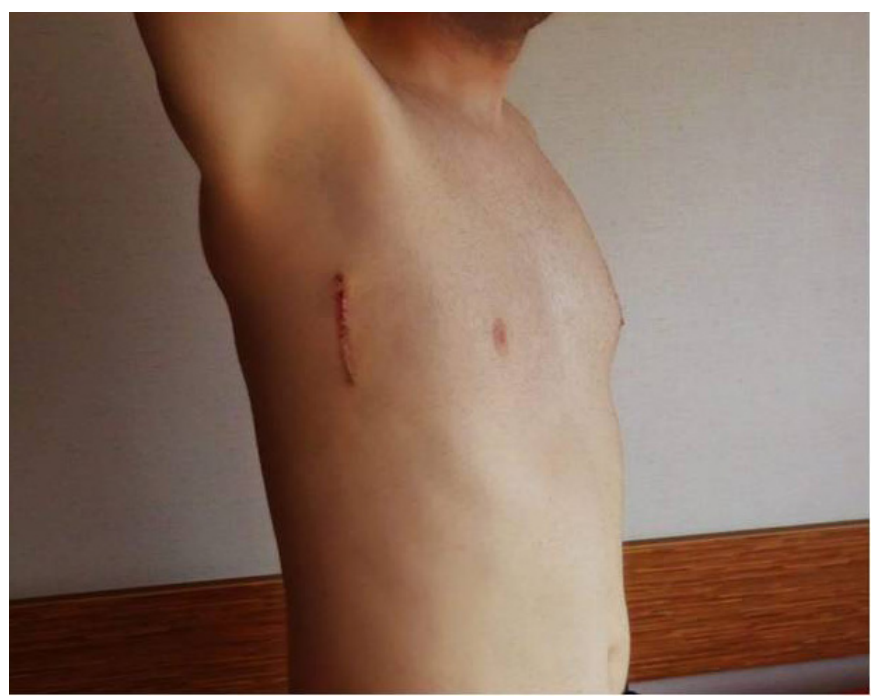

incisional pain, less requirement for pain medication both in the hospital and early period after the surgery, and a faster return to normal usual activity. ${ }^{(2-8)}$

In this our series, postoperative first day, all of the patients could abduct their right arm about 90 degrees.

A disadvantage has been use of the femoral artery for cannulation, retrograde dissection may occur, and groin complications such as groin infections, arteries requiring reconstruction can be seen and were, in fact, a source of minor morbidity to the patient. ${ }^{(20,21,22)}$ In our series, we don't have any complication about retrograde dissection and groin complications.

The major question to be asked is this: can you achieve the same quality of operation that you can do through the complete median sternotomy without complete exposure of the heart? The answer, based on our experience and the other authors which are minimally invasive surgeons, is an emphatic "yes". The quality of the valve replacement and repair in both the aortic and mitral has been exactly equal to the standart operation. There have been no perivalvular leaks in any of the valves implated, and there has been excellent visualization of the valves as to perform valve implantation or repair, and documented by intraoperative and postoperative by transesophageal echocardiography. Thus, we believe that the quality of the valve operations has not been mitigated in any way. Conversely, we have learned that in the extremely older and sick patients with a high degree of the risk and potential morbidity, these minimally invasive prosedures may not be as useful.

Finally, minimally invasive aortic and mitral valve surgery in patients without coronary disease can be done safely and accurately through small incisions. Patient satisfaction is up, return to normality is higher, and requirement for post-hospital care is less. If the same quality of the operation can be performed through a less traumatic and better cosmetic incision resulting in less hospital stay and a lower overall cost, if the operation can be performed as effectively as the operation with the standard complete median sternotomy and significantly reduce the need for post-operative care, the minimally invasive valve surgery can be prefered. 


\section{Conclusion}

Minimally invasive right vertical infra-axillary thoracotomy has two main advantages: Cosmetic appearance and patient comfort. Cosmetic appearance is very important for younger patients. The incision is so placed that the patient can not see the incision site without using a mirror. So, many patients, especially younger patients, prefer this technique to a median sternotomy and to other minimally invasive thoracotomy incisions. Nearly half of our patients were younger than 40 years. Compared to other minimally invasive techniques, we believe that the right vertical infra-axillary lateral approach is cosmetically more acceptable for patients.

Postoperative patient comfort, the patient can perform almost all activities without difficulty or discomfort, such as lying in bed in any position, arising from bed without help, using upper extremities without limitation, and early return to daily activities. Hence, higher patient satisfaction. Elderly patients have an increased risk for dehiscence of the standard sternotomy site. Overweight patients may have sleep apnea and thus can not lie in the supine position. These risks can be avoided by using this technique.

Surgical advantages: Less postoperative pain, no sternal infections, less blood loss, faster recovery, shorter intensive care unit and hospital stay, lower overall costs, lower morbidity and mortality. The quality of valve operations is not at all less with this technique.

Last, but not least, this technique presents particular difficulties for the surgeon. It is demanding, and have a learning curve. Only a dedicated team can have a successful result. 


\section{References}

1. Navia JL, Cosgrove DM. Minimally invasive mitral valve operations. Ann Thorac Surg 1996;62:1542-4.

2. Cohn LH, Adams DH, Couper GS, et al. Minimally invasive cardiac valve surgery improves patient satisfaction while reducing costs of cardiac valve replacement and repair. Ann Surg 1997;226:421-6.

3. Mihaljevic T, Cohn LH, Unic D, et al. One thousand minimally invasive valve operations: early and late results. Ann Surg 2004;240:52934.

4. Doll N, Borger MA, Hain J, et al. Minimal access aortic valve replacement: effects on morbidity and resource utilization. Ann Thorac Surg 2002;74:S1318-22.

5. Raja SG, Navaratnarajah M. Impact of minimal access valve surgery on clinical outcomes: current best available evidence. J Card Surg 2009;24:73-9.

6. Brown ML, McKellar SH, Sundt TM, et al. Ministernotomy versus conventional sternotomy for aortic valve replacement: a systematic review and meta-analysis. J Thorac Cardiovasc Surg 2009;137:670679.e5.

7. Murtuza B, Pepper JR, Stanbridge RD, et al. Minimal access aortic valve replacement: is it worth it? Ann Thorac Surg 2008;85:1121-31.

8. Modi P, Hassan A, Chitwood WR Jr. Minimally invasive mitral valve surgery: a systematic review and meta-analysis. Eur J Cardiothorac Surg 2008;34:943-52.

9. Lamelas J1 Minimally invasive aortic valve replacement: the "Miami Method".Ann Cardiothorac Surg. 2015 Jan;4(1):71-7.

10. Valdez GD, Mihos CG, Santana O, et al. Incidence of post-operative acute kidney injury in patients with chronic kidney disease undergoing minimally invasive valve surgery. J Thorac Cardiovasc Surg 2013;146:1488-93.

11. Santana O, Reyna J, Benjo AM, et al. Outcomes of minimally invasive valve surgery in patients with chronic obstructive pulmonary disease. Eur J Cardiothorac Surg 2012;42:648-52.

12. Mihos CG, Santana O, Lamas GA, et al. Outcomes of right mini-thoracotomy mitral valve surgery in patients with previous sternotomy. Ann
Thorac Surg 2011;91:1824-7.

13. Pineda AM, Santana O, Reyna J, et al. Outcomes of aortic valve replacement via right mini-thoracotomy versus median sternotomy in patients with previous cardiac surgery. J Heart Valve Dis 2013;22:50-5.

14. Lamelas J, Sarria A, Santana O, et al. Outcomes of minimally invasive valve surgery versus median sternotomy in patients 75 years or greater. Ann Thorac Surg 2011;91:79-84.

15. Santana O, Reyna J, Grana R, et al. Outcomes of minimally invasive valve surgery versus standard sternotomy in obese patients undergoing isolated valve surgery. Ann Thorac Surg 2011;91:406-10.

16. Minimally invasive mitral valve surgery--clinical experiences with a PortAccess system. Gulielmos V, Wunderlich J, Dangel M, Wagner FM, Karbalai P, Reichenspurner H, Tugtekin SM, Schueler S. Eur J Cardiothorac Surg. 1998 Oct; 14 Suppl 1:S148-53.

17. Phan K, Xie A, Tsai YC, Black D, Di Eusanio M, Yan TD. Ministernotomy or minithoracotomy for minimally invasive aortic valve replacement: a Bayesian network meta-analysis. Ann Cadiothorac Surg 2015;4(1):3-14.

18. Karimov JH, Bevilacqua S, Solinas M, Glauber M. Triple heart valve surgery through a right anterolateral minithoracotomy. Interact CardioVasc Thorac Surg 2009; 9: 360-362.

19. Karimov JH, Solinas M, Latsuzbaia K, Murzi M, Cerillo AG, GlauberM. Surgical treatment of double and triple heart valve disease through a limited single-access right minithoracotomy. Oxford Journals, Medicine \& Health, Multimedia Manual Cardio-Thoracic Surgery, Volume 2010, Issue 0122, 10.1510/mmcts.2009.004036

20. Wang D, Wu Q, Yang X, Hua Z. Minimally invasive approach for heart valve replacement: report of 73 cases, Zhonghua Wai Ke Za Zhi. 1999 Apr;37(4):243-4.

21. Tünerir B, Beşoğul Y, Yavuz T ve ark. Mitral kapak replasmanında mediyan sternotomiye alternatif bir yöntem: sağ minitorakotomi. GKDC Dergisi 1999;8: 100-5.

22. Yavuz Beşoğul, Vefa Özcan, Turhan Yavuz,.Bülent Tünerir, Recep Aslan. Açık Kalp Cerrahisinde Minimal İnvazif Sağ Anterolateral 
Minitorakotomi Deneyimlerimiz. Anadolu Kardiyol Derg, 2002; 4: 309-12

23. Ito T, Maekawa A, Hoshino S, Hayashi Y. Right infra-axillary minithoracotomy for aortic valve replacement. Ann Cardiothorac Surg 2015;4(1):57-58

24. Carpentier A, Loulmet D, Le Bret E, Haugades B, Dassier P, et al.[Open heart operation under videosurgery and minithoracotomy. First case (mitral valvuloplasty) operated with success]. C R Acad Sci III 1996;319:219-23.

25. Chitwood WR, Elbeery JR, Chapman WH, Moran JM, Lust RL, Wooden WA, et al Video-assisted minimally invasive mitral valve surgery: the ‘micromitral' operation. J Thorac Cardiovasc Surg 1997;113:413-4.

26. Mohr FW, Falk V, Diegeler A, Walther T, van Son JA, Autschbach R. Minimally invasive port access mitral valve surgery. J Thorac Cardiovasc Surg 1998;115:567-76.

27. Goldstone AB, Atluri P, Szeto WY, Trubelja A, Howard JL, MacArthur JW Jr., et al. Minimally invasive approach provides at least equivalent results for surgical correction of mitral regurgitation: a propensitymatched comparison. J Thorac Cardiovasc Surg 2013;145:748-56.

28. Davierwala PM, Seeburger J, Pfannmueller B, Garbade J, Misfeld M, Borger MA,et al. Minimally invasive mitral valve surgery: the Leipzig experience. Ann Cardiothorac Surg 2013;2:744-50.

Received: 21/07/2016

Accepted: 18/08/2016

Published: 15/09/2016

Disclosure and conflicts of interest:

Conflicts of interest were not reported.

Corresponding author:

Dr. Ahmet Refik Turgut

Mail: ahmetrt@hotmail.com 